\title{
Online petitions as actual protest practice in Russia and Germany: general and linguistic socio-cultural specific system-communicative characteristics
}

\author{
Larisa Rebrina ${ }^{1^{*}}$, Nikolay Shamne ${ }^{2}$, Elena Eltanskaya $^{3}$ and Nina Wendti $^{4}$ \\ ${ }^{1}$ Volgograd State University, 400062 pr. Universitetskij 100, Volgograd, Russia \\ ${ }^{2}$ Volgograd State University, 400062 pr. Universitetskij 100, Volgograd, Russia \\ ${ }^{3}$ Volgograd State University, 400062 pr. Universitetskij 100, Volgograd, Russia \\ ${ }^{4}$ Language and Interpreting Institute Munich, Baierbrunner Straße 28, 81379 München
}

\begin{abstract}
Conceptualization of the phenomenon of modern protest is important for understanding the current political and social space. The aim of the research is a comprehensive comparative system - communicative study based on a separate communicative practice (online petition) of modern protest in Russia and Germany in the context of changes in the information and communication space, parameters of satisfaction, dialectics of the general and linguo-sociocultural specific. In their research the authors use such approaches as integrative (allowing to use achievements in the given field of linguistics, sociology, political science, cultural studies, media psychology); system-communicative (to study the main communicative dimensions of protest practice), comparative (to determine the general characteristics and linguistic-socio-cultural specifics of the analyzed protest practice). The results obtained contribute to the further development of the provisions of the communicative theory of protest, to the comprehension of the communicative nature of social phenomena, the interaction of technological and socio-cultural changes; they can be used to optimize the management of conflict societies.
\end{abstract}

\section{Introduction}

Today's communication practices of protest illustrate not only new opportunities but also new «disadvantages» and problems associated with the globalization of the media, modern information and communication technologies and electronic democracy as an actual form of communication between citizens and authorities ; transformations of retial social mass communication, communicative experience and the subject of communication itself, mediatization of public life and the individual, new forms of collective interaction [Rebrina, Shamne, 2020a]. Online petitions are a mobilisation practice implementing direct democracy, conventional political involvement of citizens characterized as participation

* Corresponding author: lnrebrina@ volsu.ru 
(different levels of participation from «clicktivism» to initiation of protest actions [Berg, 2017]), constructive and active protest (participants of which differ in heterogeneity of behavior and motivation (activism consumers, new lobbyists, hit activists, stakeholders neue Lobbyisten, hit and run-Aktivisten, Activism Consumers und Single Issue Stakeholders [Jungherr, Jürgens, 2011]) [Rebrina, Shamne, 2020a ; Rebrina, Shamne, Eltanskaya, 2020b].

\section{Method}

The purpose of the research is to compare the system-communicative characteristics of online petitions as modern protest practices in Germany and Russia in the context of changes in the information and communication space, mediatization of the political sphere, effectiveness of the dialogue between citizens and authorities to determine their common features and linguistic and socio-cultural specifics. Protest is considered as a communicative system with specialized spacial and temporal (prototypical including chronotopic features of various discursive practices), objective (patterns of reality construction, thematization, problematization in these practices), collective and personal (communicative implementation of solidarity, construction of the addresser, addressee, their communicative behavior) dimensions with its inherent autonomy, self-validation, combination of the proactive and reactive [Barash, Antonovskiy, 2018]. Protest communication as a type of mediated political communication of media functions «inherits» the functions of the media providing information, socialization, mobilization, feedback, recreation / entertainment (communication, interactive exchange of approval, etc.) [Kazimirchik, 2014 ; Kurbatov, 2017; Oniszczuk, 2011 ; Small, Vorgan, 2009] ; communicative practices of protest - as communicative practices of conflict resolution, conflict (expressed «acute» discrepancy) - not as an anomie, but as a potentially constructive force (which determines the advisability of evaluating the studied practices according to the criterion of «satisfactoriness» of communication between the parties and involving, for this purpose, the postulates of «principled negotiation» by representatives of the Harvard school of conflictology R. Fischer and W. Ury) [Deutsch, Coleman, Marcus, 2006; Fisher, Ury, Patton, 2011]. Modern communicative protest practices are implemented in the context of technological determinism, growing virtuality as a social state and information administration offering the possibility of (milder) conflict management [Berg, 2017; Luna-Reyes, 2017; Oniszczuk, 2011].

\section{Research material}

1) German petitions available at the platform openPetition (https://www.openpetition.de, unified authentication system; pre-approval; search by set of filters (addressing, subject, status, place of filing); «support» of petitions with headings «Debate on the petition», «News of petitions» (including foreign postcommunication), «Comments of the signers», «Signers»; «Appeal to the addresser», «Statistics», «Share»); 2) petitions available at the official Russian platform «Russian public initiative» (ROI) (https://www.roi.ru; petitions with the required quota are sent to government agency; a unified authentication system on the portal «Gosuslugi (State Services)», where pattern of petition is proposed; pre-approval; search filters (addressing, subject, popularity, recentness of placement, place of submission; the decision (for/against); petition accompanying information - other initiatives of the sender, deadline for voting, number of votes total / per hour / ratio of the number of votes for and needed quotas, time of filing of the last vote; the headings «Comments» / 
«Debates», «News», «Status» are not presented, there are no statistics on signers, petitions of different status and headings; there is an interactive map of initiatives).

\section{Results}

\subsection{Spacial and temporal system-communicative dimension of online petitions in Germany and Russia}

Analysis of the space-time system-communicative dimension of German - and Russianlanguage petitions shows that they are united by such features constituting their integrative nature as a) polyfunctionality (outreach, directive and information-evaluative functions); b) discursive hybridity (combining features of political, journalistic, business and Internet discourse); c) stylistic syncretism: combination of features of the genre of journalistic genres (open letters of protest / in defense) and genres of business communication (petition / request / complaint), compared by the criteria of reasonableness, categoriality, presence / absence of a negative assessment and justification of a request / petition. Against the background of the marked similarities the studied German - and Russian-language petitions demonstrate quantitative differences of linguistic means used by the sender reflecting the multi-functionality of petitions: stylistic syncretism of German petitions is characterized, in contrast to the Russian petitions, by prone to signs of genres, official business styles, factuality; in Russian-language petitions it is more frequent to appeal to the addressee's emotions (but there are isolated cases of encouraging appeals to the addresser), frequent ignoring of the need to specify the source of information, gravitation to an informal communication register, greater criticality; a larger number of short petitions without proper justification, limited to stating the requirements (less strict moderation, censorship; while petitions on the ROI platform are distinguished by a greater uniformity of compositional structure due to the rubrication headings of the text offered by the platform).

\subsection{Collective-personal systemic-communicative dimension of online petitions in Germany and Russia}

The study of collective and personal system-communicative dimension of online petitions in Germany and Russia shows that in both cases the motivating prerequisite for addressers is their individual interest and competence in any field, since almost all addressers of German-and Russian-language petitions are the initiators of a single petition on the platforms under consideration; a feature of these protest practices in the framework of the described measurement is a complex target (a result of twovector addressing - to the users of the petition platform, with the aim of problematisation, solidarity, mobilization; to the authority as a target destination with the aim of beliefs and motivations) and integrated addresser (the author of the initiative and signers as a collective co-adresser) [Rebrina, Shamne, 2020a; Rebrina, Shamne, Eltanskaya, 2020b]; the emphasis of one of the abovementioned vectors determines dominating features of journalistic or business texts and the types of arguments used. At the same time, the addressee and the addresser receive different explication in the studied texts of petitions of two linguistic cultures. In Russianlanguage initiatives on the ROI the range of explications of the mass addressee is significantly narrower (in contrast to German-language petitions, direct appeals and appeals to users of the platform integrating compliments to the collective addressee, naming addressees in the beginning or conclusion; there are no headings «Debates» and "Comments»). In the discursive construction of the specific / targeted adressee in the Russian practice there is also a limited set of ways of explication (mainly in the header of 
the petition, single cases of explication when you claim there is no direct treatment in the initial part of the petition); general approach of shaping the image of the target recipient in both linguistic and cultural protest practices - a critical evaluation of the government's actions as a factor of solidarity (manifestation of power, in contrast to the German texts, is a peripheral phenomenon). In both countries petitions typically have a high level of addressing (for Germany it is the state; for Russia it is the federal level) characterizing the expectations of citizens and the reasons for applying (low expectations of the municipal authorities). The lack of statistics on submitted and successful petitions at different levels of addressing makes it difficult to assess the confirmation / fairness of citizens' expectations (statistics at the platform openpetition.de indicates partial fulfillment of expectations: low indicators of the frequency addressee «Federal land»). All the components of a complex addressee are explicated in the studied practices. At the same time the identity of the personal addresser is significantly more detailed in German-language petitions (for example, petitions in Russian do not contain a detailed self-representation and individual signature of the author relevant to the compared initiatives); the change in the status of signers (platform users, signers and co-addressers) is very limited in Russian-language initiatives (only in indicating the number of affirmative votes); there are no debates, comments, names of signers, their collective designations in the text of the petition and statistics at the platform). One of the ways of forming virtual solidarity within both linguistic cultures is, first of all, the "we-concept" implemented through interactive tools. However, the German-language platform provides greater publicity for the exchange of results / products of solidarity and transparency of the procedure for civil political participation and offers the possibility of combining virtual and offline activity. The implemented strategies of the addresser at German - and Russian - language petition platforms reflect a combination of trends in the growth of individualism and the desire for consolidation and show similarities (the prevalence of argumentative strategy $(61.8 \%$ and $73.5 \%$, respectively), the frequency of implementation of the self-presentation strategy) and differences: (greater representation in German-language petitions of the self-presentation strategy (20.7\% in German-and $9.35 \%$ in Russian-language texts) than the fatic strategy (17.5\% on both platforms)). At the same time, the communicative behavior of the Russianspeaking addresser is dominated by the tactics of psychological argumentation indicating (in contrast to German petitions, where the tactics of actual and psychological argumentation are equally frequent) the dominance of the fixation on mobilizing supporters from among the platform users, which entails the specifics of stylistic syncretism of these petitions (the predominance of features of journalistic texts); logical argumentation is a peripheral phenomenon in both practices. Self-presentation of the German- and Russianspeaking addresser is most often carried out by identifying with the platform users $(42.72 \%$ and $55.23 \%$, respectively), presenting their competence, awareness $(29.61 \%$ and $27.63 \%$; however, there is usually no indication of information sources confirming the accuracy of the reported information) and subjective position (11.07\% and $17.14 \%)$, in contrast to Russian, the German-speaking initiator also uses detailed self-determination and contrastive comparison with the disapproved opponent. The phatic strategy in ROI petitions is actualized by a significantly narrower range of tactics (the tactics of blaming the target addressee as a factor of solidarity prevail, that is peripheral for German-language petitions; the frequency tactics of the German addresser (indirect / direct appeal to the mass addresser or target addressee) and the low-frequency tactics of an integrating compliment to platform users are irrelevant). The lack of interactive tools at the ROI does not allow us to study the communicative behavior of the Russian-speaking mass addressee properly; at the Germanlanguage platform participants primarily use ethical and factual argumentation consolidating broad identification with other participants of the petition platform and opposing their own opinions to opponents. 


\subsection{Object system-communicative dimension of online petitions in Germany and Russia}

The quantitative features characterizing the object system-communicative dimension of online petitions in the two countries show significant differences. The largest number of initiatives indicates the interest of active users in the relevant areas and the concentration of problem situations in them. The coinciding high interest of representatives of both linguistic cultures characterizes the transport sphere; the social sphere, which attracts the active attention of active German citizens, demonstrates the uneven activity of platform users in Russia (high interest in the topic «consumers and service»; low interest in the sphere of «residential buildings and courtyards», «city infrastructure», «housing and utilities»); in contrast to German activists, issues of economy, state management and security, shortcomings in work and a negative image of officials are popular at the Russian platform; in contrast to Russian citizens, German recipients show an active interest in the areas of «education», «ecology», «culture». The largest number of signers indicating broad support for users of the platform characterizes various areas in Germany and Russia («culture», «ecology», «education», «construction» - in Germany; health, consumers and services, security, economy and finance - in Russia). The facts point to the predominant discrepancy between the interests of the active part of population and the broader public of the two countries and the different "problem index" of society spheres).

The patterns of discursive problem construction on the two petition platforms also reveal similarities and differences. In the studied protest practices there is a proactive formation of the problem (through the implementation of the problematization strategy, the strategy of reinforced or unsupported presentation of the assessment to intensify the impact) and self-description as a reactive practice solving the constructed problem. The strategy of problematization in Russian-language online petitions is implemented by a limited range of tactics (the tactics of emphasizing the duration of the current unfavorable situation and contrasting the positive representation of the previous state are not relevant); justification of the problem status in German petitions is most often implemented by pointing out the negative consequences of the current situation and blaming the opponent (the subject of power); in ROI petitions it is implemented by means of a positive assessment of the changes proposed by the addresser and a negative assessment of the state of affairs (blaming the opponent in ROI petitions is the least frequent tactic). German sender predominantly impose the assessment as shared by many or as a moral axiom (i.e., reliance on the opinion of a wide range of people, previous experience, and tradition); the Russian sender often are assessment shared by many or its own evaluation (the latter tactic is the least frequency in the German petitions), i.e. combine supported and unsupported presentation evaluation, tend to attribute greater weight to his opinion; reliance on authority is field tactics in both cultures.

\subsection{Online petitions in Germany and Russia as an actual practice of protest in the context of the mediatization of society and the individual}

Mediatization (likening of politics to a media process; reduction of politics to control of media reality; politics is a product of perception of virtual images, simulacra; dissemination of «media-representative democracy» [Baudrillard, 2015; Kazimirchik, 2014; Lundby, 2014; Stepanov, 2016;]) as an attribute of modern politics is reflected in the studied practices. The metaconcept «mediatization» allows us to understand the mutually dependent transformations of the technological and socio-cultural. The manifestations of mediatization in the studied practices of the two countries include [Rebrina, Shamne, 
2020a, Rebrina, Shamne, Eltanskaya, 2020b]: 1) simplifying reduction of the reality constructed and presented to the mass addressee (frequency of psychological arguments, non-necessity of factual substantiation of emotional arguments, removal from the communicative focus of the shortcomings of the proposed solutions, the position and arguments of the opponent, strengthening of emotional commitment);2) expanding the implosion of the social [Baudrillard, 2015] (diffuse status of the addressee and addressee, subject and object of influence, virtualization of solidarity, network structure of the community as a new form of socialality, combination of public and private, public subjectivity, expanding production of Internet content as «Self-resource» of the individual and a component of the author's identity, technical determinism of these processes); 3 ) multiplication and complication of the subject of protest communication as a reflection of the socio-psychological reasons for the mediatization of society and the individual (freedom to produce a public product as a reflection of the need to be heard and the desire to expand the «Self-resources», the implementation of the role of the addresser without the presence of media experience and/or competencies; a complex category of addresser and addressee); 4) mediatorial personalized presentation and «soft» conflict resolution (petitions as a «soft» version of legal practices and mediation function of petition platforms; individualization of suggestions and recommendations at the platform, the possibility of individual «management» of the user's personal activity); 5) transgressivity as an attribute of communicants' communicative behavior and the final product of solidarity caused by the growing pace of life and mediatization, which is reflected in the information structure, composition, language and stylistic means of texts and is focused on maximizing the purposeful «power of the text», «communicative will» of the addresser) [Lundby, 2014; Rebrina, Shamne, 2020a; Rebrina, Shamne, Eltanskaya, 2020b; Stepanov, 2016] (for example, the presence of «non - text» structural elements with a transgressive potential, i.e. images, including interactive maps, and videos as a means of visualization and complementation of perception modes; hashtags and hyperlinks as a means of optimizing the mobilization of supporters, semantic expansion and deepening, individualization of information; the modular nature of the text as a means of structuring speech and message, visualization of its information structure). Modern globalized information and communication processes, the combination of multidirectional trends in the expansion of collective interactions and individualism, the articulation of publicity and subjectivity, and the transgressiveness of influence in modern conditions of mediation and mediatization of protest cause a change in the subject of communication, the need for an adaptive mechanism of consciousness, which, according to a number of researchers, is the emerging Net-thinking, characterized by them as multi-vector nonlinear, network [Kurbatov, 2017; Pronina, 2001; Small, Vorgan, 2009]. These changes are reflected in the analyzed practices of the two countries: 1) expected readiness of communicants to deal with syncretism of language manifestations and simultaneous information of different modality; 2) the dominance of «combinatorics over syllogistics»: the importance of combining compositional elements and arguments in the context of a lack of logical constructions; 3 ) ожидаемые навыки гибкого, варьируемого (индивидуального) алгоритма обработки information; 4) new rationality manifested in the expected readiness with incomplete / redundant information and tolerance to uncertainty [см. Pronina, 2001; Small, Vorgan, 2009]; 5) some non-autonomy and a tendency to polyphony (focus on community complementarity, interaction of retial communication and mass self-communication) [cm. Kurbatov, 2017; Pronina, 2001]. 


\subsection{Online petitions of Germany and Russia in the context of the the Harvard school of conflictology postulates}

To describe the studied practices in the parameters of satisfactoriness you can use statistics of initiatives rejected by the petition platform, successful and failed to bring the expected result (unfortunately, it is presented only at openpetition.de) and (having a long successful tradition in conflict constructivization) parameters-postulates of the concept of the Harvard school of conflictology «Principled negotiation» [Fisher, Ury, Patton, 2011]. To ensure the procedure transparency at the German-language platform openpetition.de possible reasons for rejecting petitions by the platform are published; blocked petitions are placed in the socalled «Troll tower» (https://www.openpetition.de/trollturm) indicating the reasons for blocking. Rejected petitions make up approximately $0.7 \%$ of the total number of initiatives at the platform, which indicates that the recipients are mostly fulfilling the above requirements; successful petitions make up $45.01 \%$, and successful petitions make up $6.17 \%$. The largest number of blocked petitions falls on the level of addressing «State» and «Federal land», the ratio of the total number of rejected and blocked initiatives allows us to qualify the dialogue between platform users and the subject of power «Federal land» as the least satisfactory. Comparison of data on blocked petitions at different levels of addressing; correlation of these data with the subject of the petition indicates the least satisfactory and successful communication in the areas of «Human rights», «Security», «Family» and «Social sphere». The most common reasons for rejecting initiatives by the platform are inadequate arguments and lack of necessary references to a reliable data source, insults and discrimination, and subjective generalizing judgments.

The studied protest practices of the two linguistic cultures reveal features of both strategies: a rigid conflict resolution strategy and strategies of mutual compromises and protracted negotiations [Rebrina, Shamne, 2020a, Rebrina, Shamne, Eltanskaya, 2020b]. Analysis of online petitions in Germany and Russia indicates deviations from the larger (3/4) part of the postulates of successful conflict management by R. Fischer and W. Ury. The first postulate regulates the relationship between the parties and focuses them on «separating» the participants of the situation from the problem [Fisher, 2011, Patton, 2011] (identified deviations: subjective criticism without factual and logical justification; use of criticism / blame of the target recipient as a way of constructing its image, consolidating factor and tactics of the phatic strategy and problematization strategy; lack of phatic tactics for building relationships with the target recipient; insult / humiliation / discrimination as frequent reasons for rejecting German-language petitions (no data available for Russian petitions)). The second postulate prescribes communicants to emphasize interests without clinging to positions, to look for common interests as points of contact (deviations: putting interests, arguments, and the opponent's vision of the situation beyond the communicative focus; frequency of psychological argumentation; subjective opinion as a tactic of selfpresentation and assessment (more typical for Russian online petitions); increasing the status of the emotional and subjective (as alternatives to the logical and objective); categoricity and no indication of the matching interests of the addresser, co-addressers, and the target addressee). The third postulate aims the parties to identify and present a variety of objective criteria that should expand the argumentation spectrum and cannot depend on the interests of communicants (deviations: lack of appeals to authorities and precedents, "onesided" arguments are the disadvantages of the opponent's actions, the advantages of their own requirements). The fourth postulate focuses on the range of alternatives. The studied Russian - and German-language online petitions do not represent alternative opportunities, that is dictated by the genre framework of protest practice and cannot be interpreted as a rejection. Quantitative data indicate the most frequent deviations from postulates №1 and №3. The analysis also shows that the addresser and the mass addressee use a number of «forbidden arguments» [see about these arguments Madsen, 2013]: illegal reasoning (illegal 
transfer / extrapolation of judgment), the argument to compassion / argumentum ad misericordiam (using emotional commitment instead of justification), the argument to benefit / argumentum ad emilementiam (replacing the long-term perspective with private benefits), the argument to ignorance / argumentum ad ignorantiam (playing on unawareness).

\section{Conclusion}

Analysis of online petitions at German- and Russian-language platforms indicates their common integrative nature, which is manifested in their polyfunctionality, discursive hybridity, and stylistic syncretism. Russian-language online petitions are characterized by a greater attraction to the features of the journalistic style, less strict moderation of the petition platform and, as a result, less factual and significant attitude to authenticity, more emotionality, informality and criticality of communication, as well as, due to the proposed template, greater compositional uniformity. The investigated practices share common motives of the sender; the comprehensive nature of the category of the addresser and the addressee; the use of different ways of forming their images, the use of critical evaluation in the design of the image of the subject of power and as a factor of solidarity, the dominant high level target addressing; similar ways of formation and the life cycle of virtual solidarity; the dominance of the communicative behavior in which the argumentation is the strategy; the peripheral character of logical argument of the sender; preferential selfrepresentation of the addresser through identification with platform users. Russian platform is characterized by a narrower range of legends addressees and addressers; less transparency of procedures and publicity of the exchange of products solidarity; a lower frequency of a strategy of self-representation and higher frequency of phatic strategies of the sender along with the obvious dominance of psychological reasoning (predominance of installation on the mobilization of supporters); a narrower range of phatic tactics with the predominance of tactics charges the opponent; non-representation of the mass addressee's response communication. The analysis of the subject dimension shows that the studied practices of the two countries reflect the proactive and reactive nature of protest communication; common strategies for discursive problem construction; and the prevailing discrepancy between groups of objects of thematization and problematization in Russia and Germany; and qualitatively and quantitatively distinguished spectrum of tactics, strategies of problematisation and the presentation of evaluation in the German- and Russianlanguage petition, greater significance of their subjective positions for Russian senders and focusing on their own proposals, optional reinforcements of estimates. In the protest practices of both linguistic cultures mediatization is widely reflected as an attribute of modern politics and the characteristics of the emerging Net-thinking as an adaptive mechanism of consciousness. The described practices reveal the characteristics of different conflict resolution strategies, a deviation from most of the postulates of the Harvard school of conflictology aimed at constructivizing the conflict.

\section{Acknowledgments}

This work was supported by the Russian Foundation for Basic Research, grants No. 20012-00193.

This paper was financially supported by the Russian Foundation for Basic Research, grant No. 20-012-22046. 


\section{References}

1. R. E. Barash, A. Yu. Antonovskiy, A study of social movements from the systemic communication standpoint: is a scientific theory of political protest possible?, in Philosophical Journal, 11(2), 91-105. DOI: 10.21146/2072-0726-2018-11-2-91-105 (2018) (in Russ.)

2. J. Berg, Political Participation in the Form of Online Petitions: A Comparison of Formal and Informal Petitioning, in International journal of e-politics, 8(1), 14-29. (2017)

3. M. Deutsch, P.T. Coleman, E.C. Marcus, The Handbook of Conflict Resolution: Theory and Practice. San Francisco: Jossey-Bass Publishers, 1264 p. (2006)

4. R. Fisher, W. Ury, B. Patton, Getting to Yes: Negotiating Agreement Without Giving, New York: Penguin Books ( 2011)

5. J. Baudrillard, Simulyakry i simulyacii [Simulacres et Simulation - Simulacra and simulation]. Moscow: Izdatel'skij dom «Postum», 240 p. (2015)

6. P. Jungherr, Jürgens E-Petitionen in Deutschland: Zwischen niedrigschwelligem Partizipationsangebot und quasi-plebiszitärer Nutzung [E-petitions in Germany: Between low-threshold participation offer and quasi-plebiscitary use], in Zeitschrift für Parlamentsfragen [Journal of Parliamentary Issues], 1, 521-534 (2011)

7. L.V. Kazimirchik, The phenomenon of mediatization of public policy: theoretical and methodological aspect, in Political science. Theory and practice of social development, 11, 99-103 (2014) (in Russ.)

8. V.I. Kurbatov, NET-Thinking: New Realities of the Information Age, in Humanitarians of the South of Russia, 6(6), 173-181 (2017) (in Russ.)

9. L.F. Luna-Reyes, Opportunities and challenges for digital governance in a world of digital participation, in Information polity, 22. 2-3, 197-205 (2017)

10. K. Lundby, (Ed). Mediatization of Communication, Berlin: De Gruyter Mouton, 752 p. (2014)

11. P. Madsen, How to win an argument (Even when you're wrong) (Piter. St. Petersburg, 2013) (in Russ.)

12. Z. Oniszczuk, Mediatisation of Politics and Politicisation of the Media. Two Dimensions of the Relationship, in Studiów Medioznawczych, 4(47), 1-15 (2011)

13. E. E. Pronina, "Living Text": Four Styles of Net Thinking, in Moscow University Bulletin. Series. 10, Journalism, 6, 74-80 (2001) (in Russ.)

14. L.N. Rebrina, N.L. Shamne, Systemic-Communicative Dimensions of Modern Protest (based on German-Language Online Petitions), in Scientific dialogue, 3, 151-167. (2020a) (in Russ.)

15. L.N. Rebrina, N. L. Shamne, E.A. Eltanskaya, Modern protest communication in Russia and Germany: important issues in research methodology, in WUT, 10th International Conference "Word, Utterance, Text: Cognitive, Pragmatic and Cultural Aspects". The European Proceedings of Social and Behavioural Sciences EpSBS, 1505-1514. DOI: 10.15405epsbs.2020.08.174. (2020b)

16. G. Small, G. Vorgan, I-Brain: Surviving the Technological Alteration of the Modern Mind (Harper-Collins, New York, 2009)

17. V.N. Stepanov, Transgressiveness as an essential characteristic of modern media text in the world network, in Actual problems of stylistics, 2, 149-158 (2016) (in Russ.) 